\title{
Article
}

\section{The Undergraduate-Postgraduate-Faculty Triad: Unique Functions and Tensions Associated with Undergraduate Research Experiences at Research Universities}

\author{
Erin L. Dolan and Deborah Johnson
}

Department of Biochemistry, Virginia Tech, Blacksburg, VA 24061

Submitted March 25, 2010; Revised August 20, 2010; Accepted September 1, 2010

Monitoring Editor: Nancy Moreno

\begin{abstract}
We present an exploratory study of how undergraduates' involvement in research influences postgraduates (i.e., graduate and postdoctoral researchers) and faculty. We used a qualitative approach to examine the relationships among undergraduates, postgraduates, and the faculty head in a research group. In this group, undergraduates viewed postgraduates as more approachable than the faculty head both literally and figuratively. Mentorship by postgraduates presented unique challenges for undergraduates, including unrealistic expectations and varying abilities to mentor. The postgraduates and faculty head concurred that undergraduates contributed to the group's success and served as a source of frustration. Postgraduates appreciated the opportunity to observe multiple approaches to mentoring as they saw the faculty head and other postgraduates interact with undergraduates. The faculty head viewed undergraduate research as important for propagating the research community and for gaining insights into undergraduates and their postgraduate mentors. These results highlight how the involvement of undergraduates and postgraduates in research can limit and enhance the research experiences of members of the undergraduate-postgraduatefaculty triad. A number of tensions emerge that we hypothesize are intrinsic to undergraduate research experiences at research universities. Future studies can focus on determining the generalizability of these findings to other groups and disciplines.
\end{abstract}

\section{INTRODUCTION}

At research universities, postgraduates (i.e., graduate students and postdoctoral researchers) regularly assume a primary role in mentoring undergraduates in research (Gonzalez, 2001; Wood, 2003; Dooley et al., 2004). Although a growing body of research documents the positive outcomes of research experiences for undergraduates (Kremer and

DOI: $10.1187 /$ cbe.10-03-0052

Address correspondence to: Erin L. Dolan (edolan@vt.edu).

(C) 2010 E. L. Dolan and D. Johnson CBE-Life Sciences Education (C) 2010 The American Society for Cell Biology. This article is distributed by The American Society for Cell Biology under license from the author(s). It is available to the public under an AttributionNoncommercial-Share Alike 3.0 Unported Creative Commons License (http://creativecommons.org/licenses/by-nc-sa/3.0).
Bringle, 1990; Kardash, 2000; Rauckhorst et al., 2001; Hathaway et al., 2002; Bauer and Bennett, 2003; Lopatto, 2004; Seymour et al., 2004; Hunter et al., 2007; Russell et al., 2007), the ways in which undergraduates and postgraduates influence each other's training have been largely unexamined. Here we begin to address this gap in the literature by investigating in-depth the "triad" story, specifically, how the side-by-side involvement of undergraduates and postgraduates in research influences each of their research apprenticeships as well as the research practice of the faculty head. Specifically, we ask: (1) How do undergraduate research experiences (UREs) affect postgraduates' research experience? (2) How do postgraduates affect undergraduates participating in UREs? (3) How do UREs influence the research experience of the faculty who heads the research group? and (4) How does the faculty head influence the postgraduates' and undergraduates' involvement in UREs? 
Postgraduates are likely to have unique and important effects on undergraduate protégés. For example, undergraduates may reap unique benefits when they work side-byside with postgraduates in research. When compared with faculty, postgraduate mentors may offer undergraduate protégés a superior "need-based fit" because of their more recent experience with undergraduate education and their own developmental stage (Dutton and Ragins, 2006). Undergraduates may also benefit from the process of observing postgraduates in dialog with each other and the faculty head (McKendree et al., 1998). Simply the involvement of additional experts within the undergraduate-postgraduate-faculty triad may offer a "networking" function (Tenenbaum et al., 2001) that enables undergraduates to make more abundant and fruitful professional connections.

Similarly, interacting with undergraduates in research settings may provide a unique training environment for postgraduates. Many have argued that science doctoral education in its current incarnation does not develop in trainees the diverse skills they need for future careers, including communication, teaching, mentoring, partnering, teamwork, and maintaining appropriate standards and expectations (Rice, 1996; Nyquist et al., 1999; Hood, 2000; Austin, 2002; Nerad and Cerny, 2002; Smith et al., 2002; Melin and Janson, 2006). Working side-by-side with undergraduates presents opportunities for postgraduates to "engage in all aspects of research and develop a range of teaching skills" (Austin, 2002, p. 139). Early career experiences with undergraduate protégés, either directly as their mentors or indirectly through membership in a group that involves undergraduates in research, may help postgraduates become not only independent researchers but also independent mentors who are capable of guiding others in research. Yet, undergraduate education is often viewed as conflicting with research productivity (Layzell, 1996; Presley and Engelbride, 1998; Kim et al., 2003; Verburgh et al., 2007). Thus, in this study, we aim not only to characterize the outcomes for postgraduates and a faculty head of undergraduates' involvement in research, but also to identify tensions associated with their involvement. We propose that identification of these tensions can serve as the basis for testing their generalizability in a larger quantitative study and impetus for developing and evaluating strategies to mitigate them.

\section{METHODOLOGY}

Because our aim is to reveal how and why this triad functions, which can serve as the basis for determining whether it functions successfully in myriad contexts, we used a qualitative rather than quantitative approach (Anfara et al., 2002; Creswell, 2003; Ercikan and Roth, 2006). Specifically, we conducted the study in a single research group. Similar to naturalistic studies that examine patterns or variables within a single ecosystem, this approach is appropriate as a starting point for identifying and describing relationships or phenomena. Results from this kind of study are necessary as a foundation for larger-scale studies regarding the generalizability of the findings.

\section{Participants}

We selected a molecular life science research group at a large public research university in the Mid-Atlantic region of the United States for this study because: (1) it has a long history of involving undergraduates in research, (2) postgraduates have mentored most of the undergraduates, and (3) the faculty head had an interest in understanding how her group benefits (or not) from UREs. We defined undergraduates as students who were pursuing bachelor's degrees and postgraduates as individuals who were pursuing researchbased master's or doctoral degrees or training as a postdoctoral researcher. The faculty head was a professor and the supervisor for the entire research group. We chose to focus on postgraduates who had served as mentors and undergraduates who had served as protégés in UREs in order to narrow our participant pool to individuals who had developed a research relationship. Although undergraduates and postgraduates who were members of the group but did not participate in UREs could likely comment on how members of the triad influence their research experiences, we assumed that URE participants would be a more fruitful starting point for addressing our research questions.

Eleven past and present postgraduates who had mentored at least one undergraduate were invited to respond. Eight individuals (one postdoctoral researcher and seven graduate students, including six males and two females, five whites and three minorities) responded, and all agreed to participate in the study. One of the respondents had mentored just one undergraduate, and the others had mentored two to five undergraduates during their time in this research group. Of the eight respondents, one was still a member of the research group, four held faculty positions at research universities or predominantly undergraduate institutions, and three held positions at nonacademic organizations (e.g., companies, private research institutes). Regarding undergraduates, valid contact information was available for 14 of the 39 past and present undergraduates who had conducted UREs in this lab. These 14 were invited to participate. Eight responded, and all agreed to participate (one male and seven females, seven white and one minority). The research experiences of these undergraduates varied in timing and duration but all participated for a minimum of two semesters (12-wk summer experiences were counted as one semester), received research credit, and were paid a stipend. Four undergraduates chose to pursue doctoral degrees in life science, and the others pursued professional education (e.g., medical school) or careers both related and unrelated to life science research. The faculty head of the group, who is a white female, was the final respondent. At the time of the study, she had held a position as tenure-track or tenured faculty in a life science department for $15 \mathrm{yr}$ and had involved more than a dozen postgraduates and more than 40 undergraduates (either in UREs or in work-study/lab support positions) in her research group.

\section{Data Collection}

We designed our data collection to gather in-depth information about the mentoring relationships among undergraduates, postgraduates, and a faculty head within a single research group. Our aim was not to make predictions about what factors influence the outcomes of these relationships 
but rather to understand why particular outcomes may occur. Hence, we chose to collect first-hand accounts of experiences via interviews, which can then be analyzed to understand why certain outcomes are realized. For example, working with an undergraduate may at first slow down a postgraduate's research productivity, but then will improve the postgraduate's productivity as the protégé's skills develop. We included quotes that represent the range of responses rather than those that were most common to represent as best as possible the range of responses. By using this approach, we avoided privileging certain responses based on frequency. This allowed us to identify less common responses that may be greater predictors of particular outcomes. Our intention is not to generalize but to put forward a series of hypotheses that can be investigated in a subsequent quantitative study or that can serve as the basis for development of a scale-based instrument that could be used to collect data from a broadly representative sample.

We also chose to collect data using interviews because the time frame of the respondents' experiences relative to the group's history varied significantly, making real-time observation or documentation of their experiences unfeasible. The second author conducted all of the interviews to maintain consistency of interview style. Undergraduates and postgraduates were interviewed after completing their UREs in person or by phone using a semistructured protocol. The faculty head was interviewed in person using a similar approach. Interview questions (included in the Supplemental Material) were designed to explore URE characteristics and structure as well as lab members' perspectives on the impacts of UREs on all members and the group as a whole and their views of the ideal URE. The semistructured style of the interviews meant that these topics were approached at different times, yet all were addressed in each interview. We actively sought reports of positive and negative outcomes so that data collection would not be lopsided in favor of either. Respondents were invited at the end of the interview to add any comments that they felt would help the researchers develop a more complete picture of their experience. Interviews typically lasted $60 \mathrm{~min}$ and were audio-taped and transcribed for analysis.

\section{Data Analysis}

Inductive content analysis was used to construct categories representative of recurring patterns in the respondents' comments (Stake, 1995). Specifically, each interview transcript was parsed into units (i.e., specific quotes) that revealed information about the respondents' experiences. Units identified from analysis of the first transcript served as a tentative list of categories. As each transcript was analyzed, category construction continued through the emergence of new categories or the reinforcement of existing categories. As such, the categories per se represent an initial interpretation of the data. To establish internal validity and ensure correspondence of units with the categories, three researchers (i.e., the authors and a graduate student in science education who was otherwise uninvolved in the research) coded the transcripts using the constant comparative method (Merriam, 1998). Specifically, each transcript was read and coded by each coder separately. After each reading, a consensus-reaching discussion took place during which previously identified units were either (1) confirmed to fit a category (all three coders coded it as such) or (2) were tagged as having a "poor fit" (not considered further in the work described here). To ensure that no one coder dominated the discussion, each was allotted time to "make their case" if they disagreed with a category fit. During this process, new data units were identified and a few categories were merged, refined, or eliminated. With each category change, all of the transcripts were reread by the three coders and consensus was reached as described above.

\section{RESULTS}

Because of our interest in characterizing how URE-mediated interactions influence the research experiences of undergraduates, postgraduates, and a faculty head, we present our results to paint coherent pictures of the "undergraduate experience," the "postgraduate experience," and the "faculty experience" as observed in this particular research group. Each experience is framed to highlight how the actions of others in the triad transformed the respondent's research experience, either positively or negatively. For example, we categorized undergraduates' responses into themes regarding the ways postgraduates influenced their research experiences. We also noted instances where reports from one member of the triad offered unique insights into another member's experience. For example, we considered comments from the faculty head as we assembled the "undergraduate experience" and vice versa. Table 1 provides a comprehensive view of the categories. For categories and quotes, ' $\mathrm{U}$ ' indicates undergraduate, ' $\mathrm{P}$ ' postgraduate, and ' $\mathrm{F}$ ' faculty head. Pseudonyms are used throughout.

\section{The Undergraduate Experience}

The undergraduates in the group viewed postgraduates as more approachable both literally and figuratively than the faculty head. While the faculty head clearly generated the context for the URE, the postgraduates offered resources that the faculty head could not, primarily because they had fewer competing responsibilities and more flexible schedules. The postgraduates' inexperience with mentoring presented challenges, including variability in their mentoring skills and unrealistic expectations regarding undergraduates' work hours.

\section{Influence of Postgraduates on Undergraduates}

A majority of the undergraduates in the group emphasized how postgraduates were a source of help. The help that postgraduates provided was not limited to mentor-protégé pairs. Rather, several undergraduates reported that "all" of the postgraduates provided assistance when the need arose:
"Maria and Bradley a lot and Sam [all postgradu- ates]... All the grad students... especially at lab meetings, you present problems and everybody would pitch in". (U6)

The kinds of help ranged widely and included locating materials, arranging space for undergraduates to work, explaining how to use equipment, and recommending particular coursework or instructors. Undergraduates viewed postgraduates' help as more accessible than the help offered by the faculty head for both logistical and socioemotional reasons: 
Table 1. Influences of each member of the undergraduate-postgraduate-faculty triad

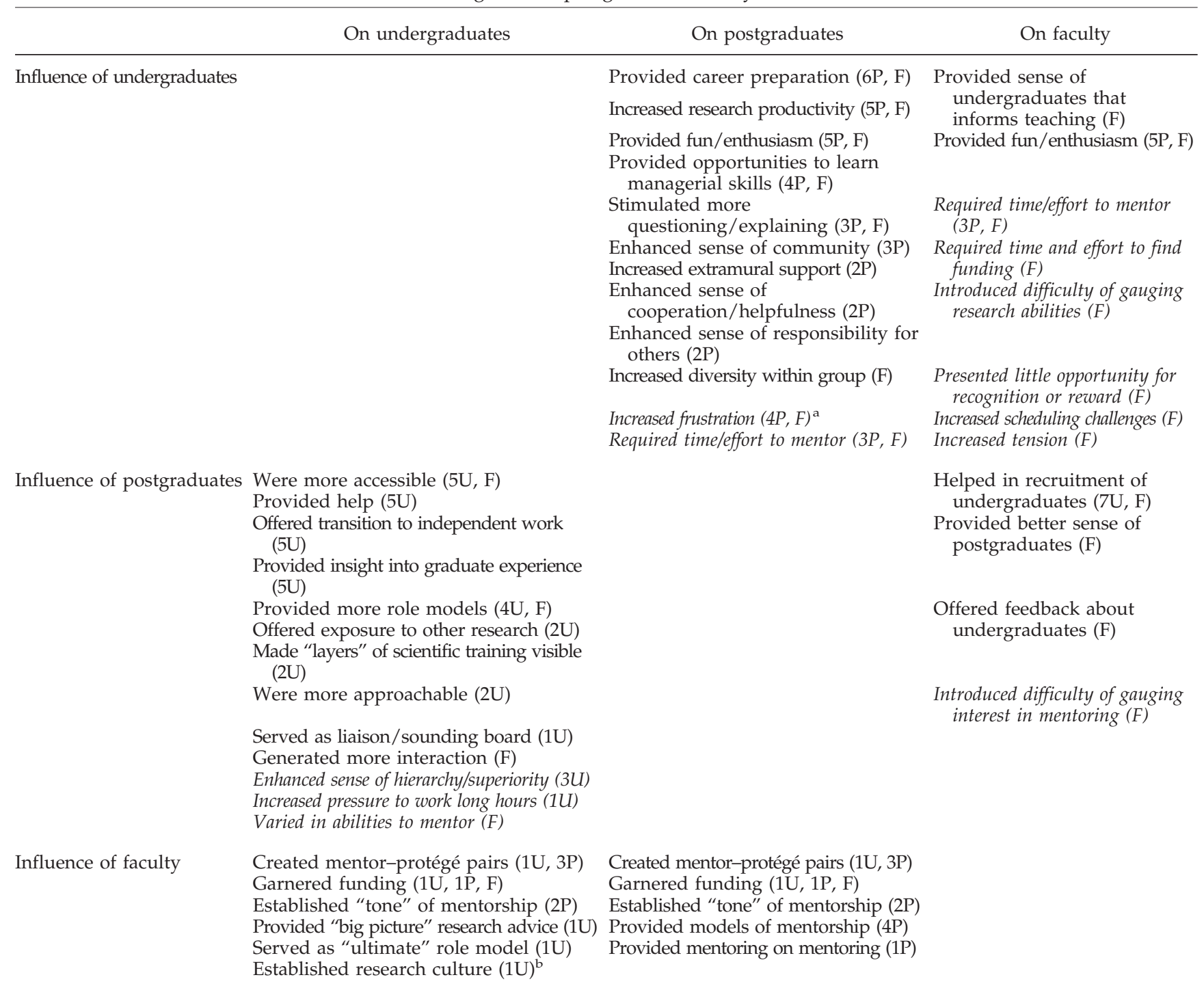

The categories identified from the viewpoint of all three members of the triad are grouped, with the member who is acting indicated in the left column and the member being acted upon indicated in the top row. For example, the ways in which undergraduates directly transformed the experiences of postgraduates is noted in the "Influence of Undergraduates" row under the "On postgraduates" column. Data sources are noted after each category, including the number of each type of respondent (e.g., $5 \mathrm{U}=$ five undergraduates whose transcripts included data that fit the category; $\mathrm{P}=$ postgraduate, $\mathrm{F}=$ faculty head). Positive and negative (italic type) categories are grouped together and listed in order of most frequent reports. This organization is designed to maximize readability rather than to place value on any particular category or theme.

aFor additional results regarding how mentoring undergraduates in research influences postgraduate mentors, see Dolan and Johnson (2009). ${ }^{\text {b}}$ See Hunter et al. (2007), Lopatto (2004), and Seymour et al. (2004) for additional research on the impact on undergraduates of research experiences mentored by faculty.

"I think just the fact that she was in her office a whole bunch and not actually in the lab. I felt like I was kind of intruding a little bit when I shouldn't have felt like that." (U1)

The faculty head's approachability was rarely an issue, and she was viewed as friendly and welcoming by all of the respondents. Yet, the proximity of the postgraduates made approaching them more straightforward. In other words, postgraduates were typically in lab and nearby, and thus easier for the undergraduates to find when they needed assistance. In contrast, the undergraduates had limited time to spend in lab because of competing commitments (e.g., coursework, extracurriculars, etc.). The tight schedules of the undergraduates and the faculty head made the postgraduates' flexibility especially appealing to the other members of the triad. A central theme of the undergraduates' com- 
ments was that the postgraduates were "always there" (i.e., in lab), while the faculty head's presence in lab was more fleeting and unpredictable. The greater availability of postgraduates may have provided a continuity of mentorship that helped the undergraduates overcome day-to-day challenges of lab work (e.g., locating materials, using equipment) and continue to make progress in their research given the finite timelines typical of UREs.

Two undergraduates viewed interacting with postgraduates as a way of getting questions answered without tarnishing the faculty head's perceptions of their knowledge and abilities:

"A lot of times it was just easier to go to one of [the postgraduates] with your questions because Carol was busy. You didn't really want to go to her with a stupid question because you didn't want her to be like, 'What?' Not that she ever would, but you always had that chance..." (U2)

One undergraduate went a step further, explaining how she viewed postgraduates as sources of ideas as well as sounding boards for discussion before approaching the faculty head.

Several undergraduates reported that working side-byside with postgraduates offered a greater breadth and depth of experience. For example, the involvement of postgraduates made the group larger and more diverse with respect to research interests. Two undergraduates noted that they were exposed to "the variety of research being conducted" through informal and formal interactions with postgraduates. One undergraduate explained that just listening to postgraduates talk as they used equipment was an opportunity for her to learn something new.

The undergraduates also reported that the postgraduates broadened their experience by offering insight into graduate education and by serving as role models. For example, four undergraduates reported that working side-by-side with postgraduates helped them understand the processes and practices of scientific training as well as the personal attributes they believed were necessary to succeed as scientists. One undergraduate explained that, when she began her work in the lab, she "didn't have any understanding of graduate school," but that she witnessed graduate students "doing their prelims and writing their proposals and then actually going to defenses." She explained that she learned "a lot about the whole process" in a way that would not have been possible "unless you were actually there watching it happen."

Another undergraduate explained that she "would have had an unpleasant awakening" had she not witnessed postgraduate training in action before deciding to pursue a Ph.D. Three undergraduates noted that the postgraduates had particular attributes, including persistence, focus, and organizational skills, that made them successful. They used these attributes as a lens for viewing their own fit with the pursuit of graduate education in science. One undergraduate reported that observing postgraduates during her URE dissuaded her from pursuing a doctoral degree because she did not want to be "like that" (i.e., like the postgraduates).

Four undergraduates viewed the postgraduates as role models and sources of inspiration. For example, one undergraduate explained that having individuals who were just slightly more advanced in their accomplishments encouraged her to "work harder" so that she could "do that someday" (i.e., what postgraduates were capable of). Perhaps these undergraduates considered achieving at the postgraduate level more realistic than doing so as a faculty member. Another undergraduate reported that the involvement of postgraduate researchers raised the level of expectations for undergraduates' research, both within and outside the lab. She explains:
"It made my research be at their (i.e., the postgradu- ates') level as opposed to if I'd been surrounded by just undergrads, I don't think I would have had a stronger research... They (i.e., other lab members) treated us (i.e., two undergraduate researchers) as if we were grad students. In fact, like a lot of professors after- ward when we graduated were confused because they didn't know we were undergrads." (U6)

The faculty head also valued how the involvement of postgraduates broadened the undergraduates' experience, primarily through offering more opportunities to interact with someone who had the time and scientific expertise to mentor them.

A majority of the undergraduates in the group reported that working with postgraduates helped them transition to doing independent research. One undergraduate spoke quite extensively about how working with postgraduates, especially conducting small projects as part of their ongoing research, added meaning to undergraduates' work:

"Once that undergraduate leaves, it (i.e., that under-
graduate's research) still benefits them and the lab as
a whole because it can tie back into maybe something
they were doing or into a paper, which is beneficial for
the lab as a whole. Because a lot of times if you start a
project that's separate from anyone else's project and
then you graduate and leave, the project just dies
off ... It's better to know that your project actually
will mean something and will go somewhere and be
carried on after you leave." (U2)

This undergraduate perceived that being held responsible for a small component of a postgraduate's research was an indication that her work was meaningful and increased the likelihood that it would be continued and possibly included in a future publication. She elaborated on this point by noting that, because postgraduates had longer tenures as members of the group, they helped ensure the continuity of the work. They could help incorporate the contributions of undergraduate researchers, which would otherwise run the risk of being disconnected or lost because of the undergraduates' limited or irregular time in the lab.

Two undergraduates emphasized the value of seeing the "layers" of experience (i.e., undergraduates, postgraduates, and a faculty head). One undergraduate explained that the involvement of individuals at different points in their training enabled everyone to "teach everyone [else] along the way as [they're] learning." She appreciated that the layered structure made visible the learning that was happening at each level. Another undergraduate reported that seeing the "levels of seniority" made the pathway from novice to expert more concrete. She welcomed the opportunity to learn from "observing" the postgraduates as they succeeded and 
erred. She thought that this experience gave her "an edge up" when she entered graduate school, because her graduate classmates who had not had this experience had "no idea" what the process of graduate education entailed.

In contrast, three undergraduates expressed concern that the layered structure created a negative sense of hierarchy that assigned authority based on rank rather than knowledge, capabilities, or experience. For some undergraduates, the sense of postgraduates' superiority arose from their own expectations for themselves. For example, one undergraduate expressed concerns about her own shortcomings when measured against the skills and knowledge of postgraduates. In other instances, the hierarchy resulted from dysfunctional actions by postgraduates, such as "scapegoating." One undergraduate explains:

\begin{abstract}
"When stuff goes wrong, it's 'Oh, the undergrads did this, the undergrads did that...' When the grad students will make comments like that to me, I'll be like, 'Hey, I've been here longer than you...'” (U4)
\end{abstract}

In this instance, the undergraduate considered his rank rather than his experience in the lab (i.e., 2 yr) as the defining factor in how postgraduates viewed his contribution. Another undergraduate acknowledged that postgraduates were further along in their training, but that a few of them "wanted to make sure [he] knew that." He explained that the experience "hardened [his] shell" such that he learned to not worry when similar situations arose in other contexts.

For the majority of undergraduates, postgraduates' steady presence in lab was an asset, but one undergraduate viewed it negatively. She "felt a lot of pressure to live at the lab" because her postgraduate mentor was "always there." She noted that she did not feel this same pressure from the faculty head because she was in her office rather than physically present in lab. This undergraduate also viewed the flexibility of postgraduates' schedules as a challenge because they could make last-minute changes in their experiments that dramatically altered how they would spend their time, while she needed to fit her research in between her other commitments.

Even though the undergraduates and the faculty head reported that the postgraduates played an essential role in UREs in the group, the faculty head also expressed concern about how the postgraduates' inexperience with teaching and mentoring might influence undergraduates' experiences in the lab. She balanced this concern by noting what postgraduates offered that she could not:

\footnotetext{
“Some graduate students don't have the greatest interpersonal skills and maybe they have done some damage ... I think mostly they're very good, patient teachers, much better than I am as far as taking the time." (F)
}

\section{Influence of Faculty on Undergraduates}

The ways in which undergraduates benefit from research apprenticeships with faculty has been the focus of several studies (Lopatto, 2004; Seymour et al., 2004; Hunter et al., 2007). Yet the undergraduates in this study reported a few ways in which they were influenced by faculty that appeared to be unique to the undergraduate-postgraduatefaculty triad. For example, one undergraduate commented that she sought advice from postgraduates about technical aspects of her project, but saved her "big picture" questions about project goals and directions for the faculty head. This strategy of seeking out postgraduates versus faculty to fulfill different needs was also clear in another undergraduate's comments about the faculty head as a role model. She viewed the faculty head as the final "level" in the group's strata, and thus the ultimate role model. Two postgraduates and an undergraduate emphasized the importance of garnering extramural funds, especially for involving undergraduates in research, and how it was the role and responsibility of the faculty head to do so. Finally, one undergraduate viewed the faculty head's establishment of a strong culture of research and training within the group as influential:

\begin{abstract}
"Part of the great history of Carol's lab is that she has this tradition of having some really outstanding, successful Ph.D.s. They go on to do interesting things, too. And that is kind of inspirational." (U5)
\end{abstract}

Each of these reports indicates how the faculty head influenced the undergraduates in the context of the triad, either because they interacted with postgraduates versus the faculty head to achieve different outcomes (e.g., technical success in experiments vs. long-term vision for research) or because they valued outcomes of interactions between the postgraduates and the faculty head (e.g., the faculty head's experience in preparing successful postgraduates).

\section{The Postgraduate Experience}

The postgraduates viewed undergraduates' involvement in the group as a means to accomplish a number of ends, for example, increasing their research productivity and extramural support for the group's research. The postgraduates also appreciated the opportunity to observe multiple approaches to mentoring as they saw the faculty head and other postgraduates interact with undergraduates. The faculty head emphasized that mentoring undergraduates improved the postgraduates' managerial skills. The postgraduates and the faculty head concurred that involving undergraduates in the group contributed to its success and served as a source of frustration.

\section{Influence of Undergraduates on Postgraduates}

The majority of the postgraduates in the group and the faculty head agreed that the undergraduates increased the amount of research that the postgraduates could accomplish because the undergraduates were people they could "trust to get things done." In some cases, the productivity of an undergraduate led directly to progress in the postgraduate's research because the undergraduate was responsible for a small component of the postgraduate's larger project. In other cases, the undergraduates' research efforts moved the group's research in new directions:

\footnotetext{
"If she [the faculty head] has an idea, [postgraduates] don't necessarily have the time to stop everything they're doing and say, 'Oh, we're going to pursue this new lead for a little while.' But an undergraduate can ... That's really nice because the [postgraduate] does not take time away from their research... If it pans out, you'll probably get into new work." (P7)
} 
Pursuing a new lead was considered by this individual to be a high-risk endeavor, which was appropriate for an undergraduate but not necessarily for postgraduates who depended upon outcomes of the research to earn their degrees or be competitive for employment.

Two postgraduates reported that the involvement of undergraduate researchers influenced the group's access to extramural funds. One postgraduate perceived that UREs were a "central theme" for grant funding, while another perceived that it made the group's grant proposals more competitive for funding:

"Honestly, it helped the funding. [Funding agencies] certainly like to have lots of people trained through their granting mechanisms at all levels. So it was always positive." (P4)

A majority of the postgraduates appreciated how undergraduates made day-to-day work more fun. For the most part, the group appreciated the "happier environment" that developed with the day-to-day involvement of undergraduates. The postgraduates valued that, unlike themselves, the undergraduates were not "stressed out" and did not yet have the "narrower view" of someone further along in their scientific training. The postgraduates also attributed changes in the "tone" of the group to the involvement of undergraduates. They reported that undergraduates gave the group a sense of community, cooperation, helpfulness, and responsibility for others. Three postgraduates and the faculty head reported that the involvement of undergraduates increased the amount of questioning and explaining that occurred within the group, especially during whole group discussions (i.e., "lab meetings"). One postgraduate explained that the presence of undergraduates "made it easier for questions to be asked" because the expectation was that individuals explain their work in a way that everyone, even the newest lab members, could understand. The faculty head's comments illustrate how she designed group interactions to achieve this:

"Our lab meetings were structured around communicating to everybody, not just the other people who completely know and have written a prospectus and understand the system, but now backing up and saying, 'OK, this is what we're doing,' and to remind everybody that this is the question and saying it in terms that everybody can understand." (F)

Some postgraduates recognized her intentions, and one adopted this approach when he became a faculty head:

\begin{abstract}
"It was a tool Carol used that I use now. When we were doing lab meetings and presenting our research, you tend to flash into what you were doing and go 90 mph and not think about the overall building of the experiment or explaining things early on. Carol would always say, 'Whoa, whoa, someone, whoever the next person in the lab is here. Back up and explain from the beginning what you're doing."' (G1)
\end{abstract}

The involvement of undergraduates also had negative impacts on the postgraduates, in some instances accentuating their powerlessness. For example, only the faculty head had the authority to include or remove undergraduate re- searchers from the group. Postgraduates were expected to work side-by-side with undergraduates and thus could not "escape," even temporarily, an undergraduate who was a particular frustration, as noted by one postgraduate:

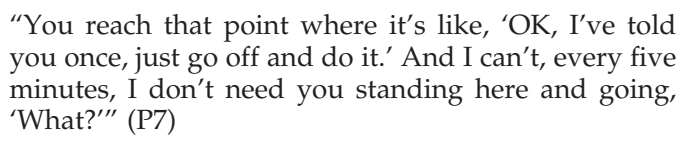

Although dysfunctional relationships appeared to be exceedingly rare within the group, this example highlights how postgraduates may have been unable to avoid interacting with undergraduates. The faculty head explained how this affected one postgraduate:
"I had that one 'wonderful' undergraduate, this more senior guy who was a real loner and he did piss off a whole bunch of people. He would go to sweet Mi- chael, my graduate student who's the nicest guy in the world, ask him for his opinion, ask him for advice, take a lot of his time and then go off and do his own thing and not listen to what Michael had told him. Michael just got so mad because he felt like he was wasting his time." (F)

\section{Influence of Faculty on Postgraduates}

Half of the postgraduates noted that the involvement of undergraduates provided multiple models of mentorship as well as opportunities for mentoring on mentoring from the faculty head. The postgraduates could observe each other and the faculty head as they mentored undergraduates:
"I definitely use her [Carol] as a model. She's very good at it. Or even watching other people mentor for that matter. Watching Maria work with Lauren [un- dergraduate]. Watching the way she did things later. I either did things that way or didn't do things that way based on how things went." (P1)

The faculty head emphasized that undergraduates' involvement in the group provided opportunities for postgraduates to learn managerial skills:

\begin{abstract}
"Managing people is the hardest thing about our job because we're not trained to do that at all ... We lie awake at night agonizing over people. It's rarely the undergraduates that cause trouble, but it's even them you worry about. Without feedback it's very hard to know what's going on so I think this addresses a real big issue in our whole career." (F)
\end{abstract}

The faculty head considered UREs to be hands-on training for postgraduates regarding how to supervise people, manage time and expectations, and tailor their "management styles" to meet the needs of different undergraduates. In addition, she viewed UREs as structured mechanism for postgraduates to get feedback about their mentoring from undergraduates, other postgraduates, and herself. She made special efforts to check in with postgraduates regularly to "make sure they were getting something out of the relationship" with undergraduate researchers and "mentor them" on how to mentor others. She saw this feedback as something that was absent from her own training and the preparation of most faculty. Two postgraduates reported that the 
faculty head set a "tone" of mentorship, emphasizing how mentoring and education were a part of the "culture" that she had "cultivated." Through her actions, the faculty head created an environment that actively supported UREs, both implicitly and explicitly.

\section{Influences on the Faculty Experience}

The faculty head viewed UREs as a critical first step in propagating the science research community, rather than as a worthwhile research activity per se. As such, her comments more often reflected the immediate costs of UREs rather than the outcomes for undergraduates or postgraduates. She did note, however, that she gained unique insights into undergraduates as a group as well as individual postgraduates from including undergraduates in her research practice.

\section{Influence of Undergraduates on Faculty}

The faculty head noted three gains she realized as a result of involving undergraduate researchers in her lab. First, she explained that UREs were contexts for her to develop more sustained and intimate relationships with undergraduates, which she would not typically do as an instructor in a course:

\section{"It's just great to be that in touch with somebody, to get to know on a real personal level. It's beyond any- thing you'll see in a course because you get to know about their families and their personal lives to some extent, what motivates them, and where they're going in ways you don't do in a course because it is a long-term relationship..." (F)}

Second, she noted that observing the postgraduates as they mentored undergraduates gave her more comprehensive insight into postgraduates' strengths and abilities, based on feedback from undergraduate protégés and her own observations. As a result, she felt better positioned to paint complete pictures of postgraduates in letters of reference:

\footnotetext{
"It comes into my letters and evaluation. When I wrote letters for Michael, for example, I wrote a whole paragraph on his interaction with his undergraduate students and his ability to work with them and what that said about him." (F)
}

Third, the faculty head appreciated the diversity that undergraduates brought to the group, each contributing his or her own unique history, background, and views to the group's efforts. She acknowledged that undergraduates brought a contagious enthusiasm and "new perspectives" to the research, by asking "incredibly naïve but very pointed questions" that encouraged the group members to think deeply about their work. She also noted that the undergraduates' naïveté could be a source of tension for the group:

“Boy, I've seen some [undergraduates] come into the lab and just hack off everybody else [laughter] ... They have to understand that you don't just touch people's stuff, or, you know, you learn all these little cultural things ..." (F)
While the postgraduates emphasized the value of UREs for research productivity and funding success of the group, the faculty head stressed the amount of time and effort she spent on acquiring funding for UREs. She explained that funding agencies were "very generous" in providing support for UREs, but that the money had to be requested each year and varied from year to year. She also noted the timeconsuming nature of mentoring undergraduates. Although she also considered training early-career graduate students to be time consuming, she knew that these trainees would contribute substantively to ongoing research because of their sustained tenure in the group. In contrast, undergraduates participated in research for shorter durations with the limited time they had available between or after classes. Even undergraduates who committed to UREs for multiple years had schedule changes that influenced the group as a whole. For example, the faculty head reported that undergraduates' schedules presented logistical challenges for arranging times for lab meetings.

In doing a "back of the envelope" calculation regarding what was accomplished research-wise by undergraduates, the faculty head figured that postgraduates could accomplish much more doing the research themselves than by mentoring undergraduates in doing the research. She explained that she mitigated this issue by accepting undergraduate researchers no later than their junior year. In addition, even though she could note on her annual evaluations the number of undergraduates researchers in her lab, her perception was that this activity was not included in the "formula" that predicted tenure or promotion decisions or other professional rewards.

\section{Influence of Postgraduates on Faculty}

In some respects the postgraduates had minimal authority in the group's dealing with undergraduates, but they played at least three pivotal roles. First, the faculty head repeatedly stated that she would never have enough time to mentor undergraduates without postgraduate involvement. Second, the postgraduates were the primary recruiters of undergraduate researchers. Seven of the eight undergraduates learned about research opportunities from postgraduates. The postgraduates were often teaching assistants in the undergraduates' laboratory courses, and they used these interactions to identify and encourage promising undergraduates to approach the faculty head about doing research. The faculty head noted that she never had to "do any advertising" for undergraduates because her postgraduates recruited them on an ongoing basis.

Third, postgraduates provided another source of feedback about the undergraduates. The faculty head used postgraduates' feedback to tailor her own interactions with undergraduates, informing her choice to "emphasize things that are going well ... or else step in if there are technical problems." Perhaps of greater impact is the role postgraduates' feedback played in her decision to keep particular students in the group in subsequent semesters. She explains:

\footnotetext{
"The [postgraduates] have a much better feel for the undergrads' abilities and potential than I have, so I rely on them heavily to flesh out my superficial impressions." (F)
} 
The faculty head explained that UREs presented interpersonal challenges for her, for example, how she could best gauge postgraduates' interest in mentoring and abilities to do so:

"I want to make sure that they want to [mentor undergraduates] . . . I'm not always sure if they're just doing it to make me happy, or if they're really genuinely wanting to do it." (F)

She also noted the challenge of gauging undergraduates' research abilities in a way that allowed her to assign them feasible projects and set reasonable expectations for their work. She repeatedly discussed how this was a challenge that she and her postgraduates faced together, by "dropping their expectations" about what undergraduates could accomplish. Her comments suggested that the challenge of gauging undergraduates' research abilities was twofold: the process of determining what undergraduates could and could not do, and coaching postgraduates in learning to navigate this process as they worked with undergraduates.

\section{DISCUSSION AND IMPLICATIONS}

These results illustrate that UREs influence, both positively and negatively, all members of a research group. The undergraduates in this study reported that the postgraduates served as sources of help and as sounding boards for undergraduates before they approached the faculty head for guidance. The postgraduates offered unique resources when compared with the faculty head, including enhanced accessibility and approachability. For example, the undergraduates sought postgraduates for technical advice, likely because accomplishing technical aspects of the work was integral to their day-to-day activities. In contrast, these undergraduates approached the faculty head for a "bigger picture" view of their work, which again fit with the faculty head's role in the group. In addition, the undergraduates sometimes saw approaching the postgraduates with a question as less risky than approaching the faculty head, perhaps because they viewed the faculty head as someone they wanted to impress. Collectively, these findings suggest that the triadic mentoring structure of undergraduate-postgraduate-faculty head may allow for specialization that is not possible in other structures. In other words, neither the postgraduate nor the faculty head needs to provide all of the functions of a research mentor.

The undergraduates' comments on how working with postgraduates helped them transition to independent work echoed the sentiments reported by doctoral students who engaged in research as undergraduates (Delamont and Atkinson, 2001). Watching postgraduates navigate the process of socialization into the scientific community has the potential to validate the undergraduate's own struggle and provide multiple models handling the "reality shock" of scientific training. Although it was not the focus of this study, peer networks have been shown to facilitate minority students' participation in research (Hurtado et al., 2008). Thus, the opportunity to work side-by-side with postgraduates may enhance the recruitment and retention of underrepresented students into science research careers. Institutional support for UREs can offer undergraduates and postgradu- ates alike another venue for developing informal relationships that foster socialization into the scientific community.

The faculty head expressed concerns about the impact of postgraduates' inexperience with mentoring. Certainly, similar concerns could be expressed about faculty, who also vary in their mentoring skills and philosophies. Yet, within a research group, several postgraduates with differing mentoring approaches and abilities are present day-to-day, making these differences more concrete and visible to protégés. In addition, the faculty head must grapple with how to choose mentors. If a postgraduate has weaker interpersonal skills but a sincere interest in serving as a mentor, the faculty head must decide whether to use an undergraduate's research experience as a training experience for the postgraduate. Also, if postgraduates view the faculty head's selection of them as a mentor as a validation of their knowledge, skills, and development as a scientist (Dolan and Johnson, 2009), a faculty head who chooses certain postgraduates as mentors may implicitly signal to others that they are somehow lacking.

Taken together, these results reveal key distinctions in the movement from novice to expert. Specifically, postgraduates had some expertise as independent researchers but had not yet developed the expertise that faculty have to mentor others in research. For the most part, the undergraduates in this study had not yet become capable of conducting independent research and appreciated the opportunity to watch how postgraduates did it. Perhaps the practices of faculty as individuals who guide others in independent research are too distant, unrelated, or unachievable when viewed by undergraduate apprentices, while accomplishing the tasks of postgraduates appears more doable. As such, observing postgraduates in their work may serve as an intellectual scaffold for undergraduates pursuing scientific careers in academia.

Although further study is needed to determine the extent to which these outcomes are a reflection of dyadic relationships between postgraduate mentors and undergraduate protégés or simply the side-by-side involvement of undergraduates and postgraduates in research, we believe that these results reveal five tensions that are intrinsic to UREs at research universities (Table 2). We describe these tensions here:

\section{Tension 1}

Enhancing Socialization vs. Creating a Negative Sense of Hierarchy. All of the undergraduates in this study reported one or more ways that postgraduates helped them develop as scientists. Yet, three undergraduates described how postgraduates contributed to a negative sense of hierarchy in the group. Thus, including postgraduates in UREs provides the opportunity for undergraduates to become socialized into the scientific community, but also has the potential to exacerbate negative hierarchies with the group.

\section{Tension 2}

Increasing Research Productivity vs. Requiring Time and Effort to Train. The postgraduates and the faculty head agreed that, in some cases, undergraduates enhanced research productivity but also required significant time and effort to train (see also Dolan and Johnson, 2009). 
Table 2. Tensions in the undergraduate-postgraduate-faculty triad

1. Postgraduates enhance undergraduates' socialization into the scientific community

2. Undergraduates increase research productivity of the group

3. Undergraduates need high-quality mentorship

4. Faculty involve undergraduates in research to propagate the scientific community

5. Faculty must gauge postgraduates' genuine interest in mentoring
Postgraduates generate a sense of hierarchy

Undergraduates require additional time and effort to train

Postgraduates vary in their mentoring abilities and need opportunities to build mentoring skills

Faculty are not recognized or rewarded for involving undergraduates in research

Faculty must identify when postgraduates are ingratiating by volunteering to mentor

\section{Tension 3}

Undergraduates' Need for High Quality Mentorship vs. Postgraduates' Need to Develop Mentoring Skills. Mentoring undergraduates has the potential to engage postgraduates in learning about the "many aspects of faculty work" (Austin, 2002; p. 114). Yet, postgraduates vary in their mentoring skills. If UREs at research universities are venues for postgraduates to develop managerial and mentoring skills, then the quality of the undergraduate's experience may suffer as postgraduates develop the relevant skills.

\section{Tension 4}

Propagating the Scientific Community vs. Not Being Recognized or Rewarded for Doing So. The faculty head reported more negative outcomes of UREs, including the amount of time necessary to garner funds to support UREs and the lack of recognition or reward for doing so. Clearly, she has every intention of continuing to involve undergraduates in research because of its importance in preparing the next generation of researchers, but this aim is in tension with the personal and professional costs to her.

\section{Tension 5}

Gauging Postgraduates' Genuine Interest in Mentoring vs. Ingratiating. Postgraduates' mentoring of undergraduates makes it possible for the faculty at research universities to involve undergraduates in research. Yet, the faculty head in this study expressed concern about her inability to gauge genuine interest of postgraduates versus their agreeing to mentor out of a sense of obligation or in order to win favor with her or (i.e., ingratiating).

Our point is not that research universities do not engage undergraduates in research or fail to see UREs as valuable contexts for learning. Rather, we believe that research universities are contexts that can produce unique tensions within UREs. Steps are already being taken to mitigate these tensions. Federal and philanthropic agencies are building a culture that values undergraduate involvement in research. URE funding is now one of the "explicit structures that encourage community-accepted types of participation over other types" (Barab et al., 2002; p. 494), in this case, tipping the balance toward engaging undergraduates in research. If further research reveals positive outcomes of UREs for postgraduates and faculty, faculty may tip their own cost-benefit analysis of UREs toward the "benefit" side.
Others have reported that UREs are key factors in confirming undergraduates' decisions to pursue further education or careers in science research (Lopatto, 2004; Seymour et al., 2004; Hunter et al., 2007). Perhaps undergraduate-postgraduate dyads present a greater risk for ineffective or dysfunctional mentoring and thus for discouraging undergraduates from pursuing these educational and career paths. Undergraduates may perceive that all postgraduate research apprenticeships resemble those they observed in their UREs, which may be disincentive for them to pursue further education, as was the case with one undergraduate in this study. Examination of the specific knowledge, skills, and abilities required for mentoring undergraduate researchers as well as how these characteristics can be fostered in postgraduates, such as through mentoring training programs (e.g., Handelsman et al., 2005), may ease the faculty's challenge in gauging postgraduates' fit with mentoring tasks and help avoid the risk of ingratiating.

These findings are exploratory in nature and intended to serve as the groundwork for a larger study to investigate how UREs at research universities influence all members of the undergraduate-postgraduate-faculty triad. Further research is needed to determine whether these tensions are specific to this research group or representative of the larger community, and to yield insights into how to navigate or negotiate such tensions.

\section{ACKNOWLEDGMENTS}

We thank all the respondents of this study. We thank Kathryn Smith and Chevon Thorpe for their assistance with coding; Iris Alkaher, David Lally, Katherine Nielsen, Deniz Peker, and Rebecca Smith as well as the monitoring editor and reviewers for their careful reading and thoughtful feedback; and Robert Knee for discussions about person-job fit and ingratiation. Support for this research was provided by a grant from the National Science Foundation (NSF; MCB0445878). Its contents are solely the responsibility of the authors and do not necessarily represent the official views of NSF.

\section{REFERENCES}

Anfara, V. A., Jr., Brown, K. M., and Mangione, T. L. (2002). Qualitative analysis on stage: making the research process more public. Educ. Res. 31, 28-38.

Austin, A. E. (2002). Creating a bridge to the future: preparing new faculty to face changing expectations in a shifting context. Rev. High. Educ. 26, 119-144. 
Barab, S., Barnett, M., Squire, K. (2002). Developing an empirical account of a community of practice: Characterizing the essential tensions. J. Learn. Sci. 11, 489-542.

Bauer, K. W., Bennett, J. S. (2003). Alumni perceptions used to assess undergraduate research experience. J. High. Educ. 74, 210-230.

Creswell, J. W. (2003). Research Design: Qualitative, Quantitative, and Mixed Method Approaches ( $2^{\text {nd }}$ ed.), Thousand Oaks, CA: Sage Publications.

Delamont, S., Atkinson, P. (2001). Doctoring uncertainty: mastering craft knowledge. Soc. Stud. Sci. 31, 87-107.

Dolan, E. L., and Johnson, D. (2009). Toward a holistic view of undergraduate research experiences: an exploratory study of impact on graduate/postdoctoral mentors. J. Sci. Educ. Technol. 18, 487500 .

Dooley, D. A., Mahon, R. M., and Oshiro, E. A. (2004). An undergraduate research opportunity: collaboration between undergraduate and graduate students. J. Food Sci. Educ. 3, 8-13.

Dutton, J. E., Ragins, B. R. (Eds.). (2006). Exploring Positive Relationships at Work: Building a Theoretical and Research Foundation, Mahwah, NJ: Lawrence Erlbaum.

Ercikan, K., and Roth, W-M. (2006). What good is polarizing research into qualitative and quantitative? Educ. Res. 35, 14-23.

Gonzalez, C. (2001). Undergraduate research, graduate mentoring, and the university's mission. Science 293, 1624-1626.

Handelsman, J., Pfund, C., Lauffer, S.M., Pribbenow, C.M. (2005). Entering Mentoring: A Seminar to Train a New Generation of Scientists, Madison, WI: Board of Regents of the University of Wisconsin.

Hathaway, R. S., Nagda, B. A., and Gregerman, S. R. (2002). The relationship of undergraduate research participation to graduate and professional education pursuit: an empirical study. J. Coll. Student Dev. 43, 614-631.

Hood, L. (2000). Re-envisioning the PhD: Perspectives from both academia and industry. Keynote address at Re-envisioning the $\mathrm{PhD}$ : A Working Conference, Seattle, WA, April 13-15.

Hunter, A.-B., Laursen, S. L., and Seymour, E. (2007). Becoming a scientist: the role of undergraduate research in students' cognitive, personal, and professional development. Sci. Educ. 91, 36-74.

Hurtado, S., Eagan, M. K., Cabrera, N. L., Lin, M. H., Park, J., and Lopez, M. (2008). Training future scientists: predicting first-year minority participation in health science research. Res. High. Educ. $49,126-152$

Kardash, C. M. (2000). Evaluation of an undergraduate research experience: perceptions of undergraduate interns and their faculty mentors. J. Educ. Psychol. 92, 191-201.

Kim, M. M., Rhoades, G., and Woodard, D. B. (2003). Sponsored research versus graduating students? Intervening variables and unanticipated findings in public research universities. Res. High. Educ. $44,51-82$.

Kremer, J. F., and Bringle, R. G. (1990). The effects of an intensive research experience on the careers of talented undergraduates. J. Res. Dev. Educ. 24, 1-5.
Layzell, D. T. (1996). Faculty workload and productivity: recurrent issues with new imperatives. Rev. High. Educ. 19, 267-282.

Lopatto, D. (2004). Survey of undergraduate research experiences (SURE): first findings. Cell Biol. Educ. 3, 270-277.

Merriam, S.B. (1998). Qualitative Research and Case Study Applications in Education, San Francisco, CA: Jossey-Bass Publications.

McKendree, J., Stenning, K., Mayes, T., Lee, J., and Cox, R. (1998). Why observing a dialogue may benefit learning. J. Comput. Assist. Learn. 14, 110-119.

Melin, G., and Janson, K. (2006). What skills and knowledge should a $\mathrm{PhD}$ have? Changing preconditions for $\mathrm{PhD}$ education and post doc work. In U. Teichler (Ed.), The Formative Years of Scholars, Wenner-Gren International Series Volume 83 (pp. 105-118). London: Portland Press.

Nerad, M., and Cerny, J. (2002). Postdoctoral appointments and employment patterns of science and engineering doctoral recipients ten-plus years after Ph.D. completion. Communicator XXXV, 1-6.

Nyquist, J. D., Manning, L., Wulff, D. H., Austin, A. E., Sprague, J., Fraser, P. K., Calcagno, C., and Woodford, B. (1999). On the road to becoming a professor: the graduate student experience. Change 31, $18-27$.

Presley, J. B., and Engelbride, E. (1998). Accounting for faculty productivity in the research university. Rev. High. Educ. 22, 17-38.

Rauckhorst, W. H., Czaja, J. A., and Baxter Magolda, M. (2001) Measuring the impact of the undergraduate research experience on student intellectual development. Paper presented at Project Kaleidoscope Summer Institute, Snowbird, UT, July 18-21.

Rice, R. E. (1996). Making a place for the new American scholar. New Pathways Inquiry No. 1. Washington, DC: American Association for Higher Education.

Russell, S. H., Hancock, M. P., and McCullough, J. (2007). The pipeline: benefits of undergraduate research experiences. Science $316,548-549$

Seymour, E. L., Hunter, A.-B., Laursen, S., and DeAntoni, T. (2004). Establishing the benefits of research experiences for undergraduates: first findings from a three-year study. Sci. Educ. 88, 493-594.

Smith, S. J., Pedersen-Gallegos, L., and Riegle-Crumb, C. (2002). The training, careers, and work of Ph.D. physical scientists: not simply academic. Am. J. Physics. 70, 1081-1092.

Stake, R. E. (1995). The Art of Case Study Research, Thousand Oaks, CA: Sage Publications.

Tenenbaum, H. R., Crosby, F. J., and Gliner, M. D. (2001). Mentoring relationships in graduate school. J. Vocat. Behav. 59, 326-341.

Verburgh, A., Elen, J., and Lindblom-Ylanne, S. (2007). Investigating the myth of the relationship between teaching and research in higher education: a review of empirical research. Stud. Philos. Educ. $26,449-465$.

Wood, W. B. (2003). Inquiry-based undergraduate teaching in the life sciences at large research universities: a perspective on the Boyer Commission report. Cell Biol. Educ. 2, 112-116. 